\title{
Evaluating the bones of adaptive learning: Do the initial promises really increase student engagement and flexible learning within first year anatomy subjects?
}

\author{
Kelly Linden, Louise Ann Pemberton, Lucy Webster
}

Faculty of Science, Charles Sturt University, Australia.

\begin{abstract}
Knowledge of human anatomy is essential in first-year undergraduate allied health courses. Traditionally this discipline has used time and resource intensive laboratory classes, however recent changes in resourcing and student learning preferences have led to a combination of pedagogical approaches being used. The aim of this study was to examine whether the use of Smart Sparrow adaptive and interactive online resources provided real flexibility in learning and influenced both student engagement and motivation to learn for allied health students studying first year anatomy. Twenty adaptive online anatomy lessons were created. These adaptive lessons were evaluated with (i) a student survey and (ii) inbuilt learning analytics $(n=157)$. Our results showed that a total of $96 \%$ of students agreed or strongly agreed that the resources enhanced overall engagement in the subject and $96 \%$ found the resource easy to access. Overall our findings revealed that students overwhelmingly engaged with the lessons, and selfreported improvements in their learning through repeated use of flexible and adaptive learning resources.
\end{abstract}

Keywords: Adaptive learning; flexible learning; assessment; allied health education; anatomy education. 


\section{Introduction}

Success in human functional anatomy is essential for students enrolled in allied health courses with failure often resulting in slower course progression and/or course attrition (Kruzicevic et al., 2012). Anatomy subjects at Charles Sturt University (CSU) are service taught, content heavy and often challenging for students. Some students bring prior learning to the classroom whereas others have no knowledge of anatomy whatsoever, resulting in diverse student cohorts. This combined with various student learning styles presents ongoing learning and teaching challenges for the academic particularly as disengagement is common when the content is perceived as "just too difficult". Traditionally, anatomy has been taught using conventional strategies including lectures, tutorials and laboratory classes. However, computer based learning resources have become commonplace in the curriculum particularly for medical students (Green et al., 2018) as evidence suggests that the best way to teach anatomy is with a combination of pedagogical strategies (Estai \& Bunt, 2016).

Contemporary online, adaptive learning experiences that are designed for high engagement, yet are flexible to the needs of learners, present a unique way to address challenges in teaching large, diverse student cohorts. These interactive learning resources provide flexible learning opportunities for students where two key factors, pace of learning and flexibility, are under their control (De Boer \& Collis, 2005). Adaptive learning adjusts the level of instruction in response to individual student responses to assist in personalisation of instruction and provides deep and rich learning experiences (Adams Becker et al, 2018). One example of an adaptive learning design platform is Smart Sparrow which has been successfully implemented into a range of undergraduate disciplines (Polly et al., 2014; Makransky et al., 2016; Wong et al., 2015). Success with adaptive learning technologies has also been reported in medical courses (Green et al., 2018), however there is little published data evaluating adaptive learning resources for mixed student cohorts in any discipline, including anatomy.

The overall objective of this study was to analyse students' perceptions of learning from a series of online adaptive anatomy lessons. In particular, we examined whether the adaptive lessons provided a flexible learning environment and influenced student engagement and learning within a diverse cohort of first year allied health students studying anatomy.

\section{Lesson Design}

\subsection{Participants}

One hundred and fifty seven first-year allied health undergraduate students enrolled in an introductory human anatomy subject in 2016 and 2017 participated in the evaluation of the 
adaptive lessons. The students were enrolled in the Bachelor of Podiatric Medicine, Bachelor

of Occupational Therapy, Bachelor of Physiotherapy or the Bachelor of Health and Rehabilitation Science. Ethics approval for this study was received from the CSU Research Ethics Committee (HREC Protocol No: EC00116 \& H16057).

\subsection{Development of adaptive lessons, data collection and lesson evaluation}

The Adaptive Learning Platform developed by Smart Sparrow (Smart Sparrow, 2018), was used to create twenty novel adaptive anatomy lessons. All lessons were designed by a single academic within a teaching session. High resolution photographs of specimens and models that covered over $95 \%$ of the 500 structures taught in the subject were incorporated into the lessons. Two styles of high quality lessons were designed to assist students in their learning and to prepare them for weekly practical classes and assessment items: the first ten lessons focused on building student knowledge with drag and drop style questions (Figure $1 \mathrm{~A}$ and $\mathrm{B})$; the second ten lessons included short answer questions requiring comprehension (Figure 1C and D). The 20 lesons were integrated into a high quality, modern interface to allow easy navigation for students (Figure 2). Immediate adaptive feedback built into each lesson was provided to students based on their individual responses. Types of feedback included (i) an indication of number of correct and incorrect answers, (ii) an additional two attempts for incorrect responses, (iii) display of all correct answers after three attempts and (iv) redirection to a video of the academic pointing to the structure and correctly naming it.

Participants evaluated the adaptive online lessons by consenting to one or both of the following: (1) completing a survey $(\mathrm{n}=157)$; and (2) granting access to Smart Sparrow interaction log file data and demographic data $(n=124)$.

The survey contained 12 questions measured on a 5-point Likert scale to assess (i) student motivation and engagement with the lessons and (ii) perceived student learning from completing the lessons. The remaining 8 questions were a combination of multiple-choice and open-ended items. The open-ended questions related to method of accessing the resource, thoughts on design of the learning activities, best and worst features of the adaptive lessons and suggestions for improvements. 


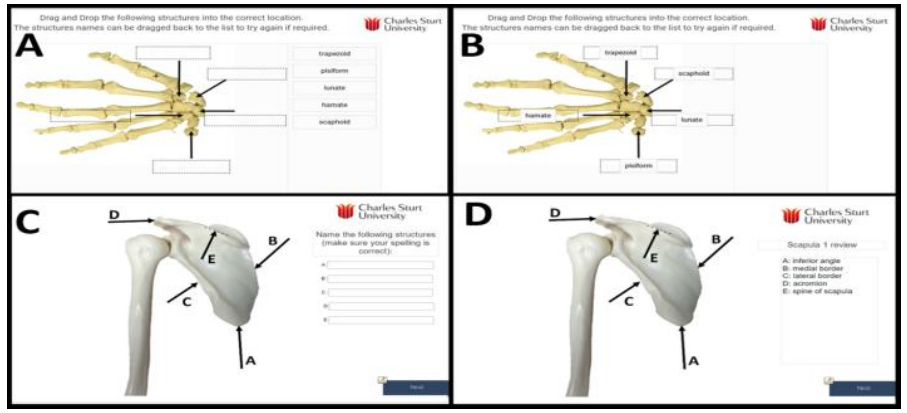

Figure 1. Screenshot of lesson content.

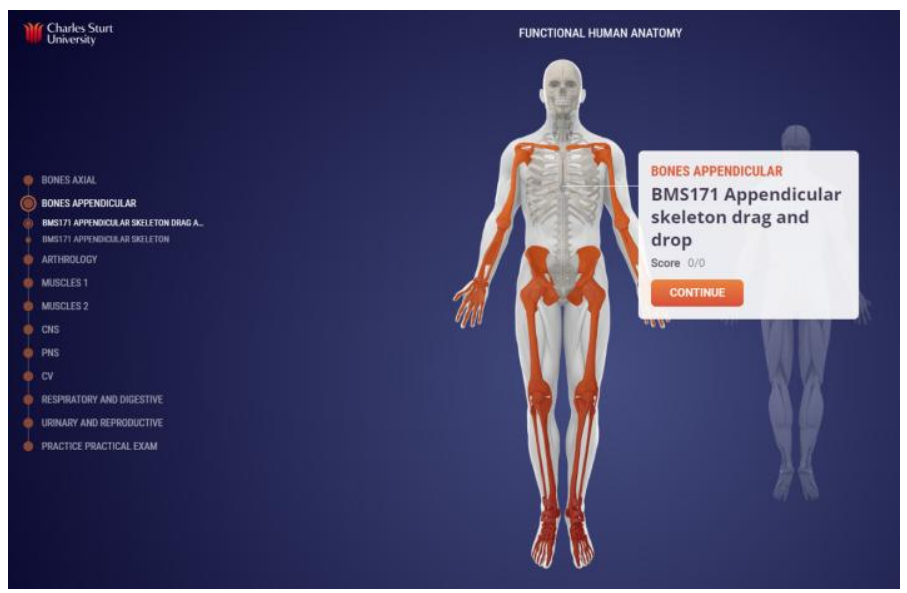

Figure 2. Smart Sparrow interface showing list of available lessons

\section{Results}

The survey data in combination with analytics revealed that the adaptive lessons were used extensively and repetitively with students not only finding the lessons engaging, but also reporting that the activities assisted with learning and preparedness for practical laboratory classes. The responses were grouped under the following three themes: Engagement and flexibility; Student Learning; and Preparedness for laboratory classes.

\subsection{Engagement and Flexibility}

Of the 157 students that completed the survey (average age $22 \pm 6.6$; mean \pm standard deviation), $96 \%$ found the resource easy to access. Students were asked where they accessed the resource with most indicating multiple locations of "home" and "university campus". Thirty five percent of students reported completing all of the available lessons and $30 \%$ of students completed each lesson five or more times (Table 1). 
Overwhelmingly, students self-reported that the adaptive lessons were interesting and engaging. A total of $96 \%$ of students agreed or strongly agreed that the resources enhanced overall engagement in the subject while $85 \%$ of students found that the interactive resources were fun (Table 2). This is evidenced by the following student comments:

"Overall a great program, extremely helpful and engaging (mixes up the way I studied)." Student 69, 2017

"It was visually interactive which meant I could complete it repetitively and not get bored." Student 61, 2017

“Felt like playing computer games - fun!" Student 65, 2016

Table 1. Method of access for adaptive lessons. Total numbers for each statement vary as students could select multiple options.

\begin{tabular}{lccccc}
\hline $\begin{array}{l}\text { What proportion of the interactive online } \\
\text { resources did you complete? }\end{array}$ & $\mathbf{1 0 0 \%}$ & $\mathbf{5 0 - 1 0 0 \%}$ & $<\mathbf{5 0 \%}$ & $\mathbf{0 \%}$ & $\mathbf{n}$ \\
& $35 \%$ & $57 \%$ & $7 \%$ & $1 \%$ & 153 \\
$\begin{array}{l}\text { How many times did you complete each of } \\
\text { the interactive online activities? }\end{array}$ & once & twice & $\mathbf{3}$ to 4 & $>\mathbf{5}$ & $\mathbf{n}$ \\
& $15 \%$ & $25 \%$ & $29 \%$ & $30 \%$ & 150 \\
I accessed the interactive resources from: & home & work & uni & other & $\mathbf{n}$ \\
& $51 \%$ & $3 \%$ & $45 \%$ & $1 \%$ & 267 \\
$\begin{array}{l}\text { I accessed the interactive online resources } \\
\text { using: }\end{array}$ & mobile & tablet & laptop & desktop & $\mathbf{n}$ \\
& $14 \%$ & $10 \%$ & $63 \%$ & $13 \%$ & 221 \\
\hline
\end{tabular}

\subsection{Student Learning}

Ninety six percent of students reported that they learnt a lot by using the resources and that completing the lesson helped $91 \%$ to identify priorities for learning. Importantly, the resources made learning more efficient for $88 \%$ of students. A total of $93 \%$ of students agreed or strongly agreed that resource flexibility assisted in their learning and catered for a range of learning styles (Table 2). This is evidenced by the following comments:

“Catered for different styles of learning." Student 69, 2016

"It really helped cement knowledge \& show where I needed to improve." Student 56, 2017

"All the questions really tested me, and I learnt a lot about what I needed to learn more of, and how to spell structures." Student 31, 2017 
Seventy nine percent of students agreed or strongly agreed that feedback provided in the online lessons enhanced their learning (Table 2). Two students specifically commented that this function was the best feature of the subject.

"Easy to use, gives you instant feedback." Student 66, 2017

“Good feedback easy to use, good for highlighting gaps in knowledge." Student 43, 2016

\subsection{Preparedness for practical class}

Eighty six percent of students either agreed or strongly agreed that the online lessons increased their confidence in the practical laboratory classes and $95 \%$ of students reported that the online lessons consolidated their learning after the relevant laboratory class was completed.

\section{Discussion and Conclusion}

This study provides strong self reported student evidence for the effectiveness of adaptive learning resorces in teaching anatomical content to large, service taught diverse cohorts. In particular, students commented on their motivation and curiosity to repeat the lessons because they were visually engaging and catered to individual learning styles. They also self reported improvements in their learning and laboratory preparedness through repeated use of the flexible and adaptive learning resources. This finding is in line with other previous reports (Chen, 2010; Wong et al., 2015, Green et al., 2018). While we do acknowledge that one of the limitations of this study was the reliance on self reporting, future work will aim to gather quantitative data to determine the relationship between completion of the adaptive lessons and subject success. 
Table 2. Self-reported engagement, learning $\&$ preparedness from the adaptive lessons. $1=$ =Strongly disagree, $2=$ Disagree, $3=$ Neutral, $4=$ Agree, $5=$ Strongly agree

\begin{tabular}{|c|c|c|c|c|c|c|}
\hline & 1 & 2 & 3 & 4 & 5 & $\mathbf{n}$ \\
\hline \multicolumn{7}{|l|}{ Engagement } \\
\hline $\begin{array}{l}\text { I found using the interactive online resources } \\
\text { enhanced my overall engagement with this subject }\end{array}$ & $0 \%$ & $0 \%$ & $4 \%$ & $35 \%$ & $61 \%$ & 152 \\
\hline $\begin{array}{l}\text { My experience with the interactive online } \\
\text { resources was fun }\end{array}$ & $0 \%$ & $3 \%$ & $12 \%$ & $47 \%$ & $38 \%$ & 152 \\
\hline \multicolumn{7}{|l|}{ Student Learning } \\
\hline $\begin{array}{l}\text { I learnt a lot by using the interactive online } \\
\text { resources }\end{array}$ & $0 \%$ & $1 \%$ & $3 \%$ & $38 \%$ & $\mathbf{5 8 \%}$ & 152 \\
\hline $\begin{array}{l}\text { The interactive online resources enhanced my } \\
\text { motivation to learn about the topic/s }\end{array}$ & $0 \%$ & $1 \%$ & $13 \%$ & $47 \%$ & $39 \%$ & 152 \\
\hline $\begin{array}{l}\text { The interactive online resources helped me to } \\
\text { identify priorities for my learning }\end{array}$ & $0 \%$ & $1 \%$ & $8 \%$ & $38 \%$ & $\mathbf{5 3 \%}$ & 152 \\
\hline $\begin{array}{l}\text { Using the interactive online resources made my } \\
\text { learning more efficient (saved time) }\end{array}$ & $0 \%$ & $1 \%$ & $11 \%$ & $41 \%$ & $47 \%$ & 152 \\
\hline $\begin{array}{l}\text { Having access to the interactive online resources } \\
\text { met my needs for flexibility in my learning }\end{array}$ & $0 \%$ & $0 \%$ & $7 \%$ & $45 \%$ & $48 \%$ & 152 \\
\hline $\begin{array}{l}\text { The interactive online resource provided feedback } \\
\text { that enhanced my learning }\end{array}$ & $0 \%$ & $3 \%$ & $18 \%$ & $45 \%$ & $34 \%$ & 152 \\
\hline Preparedness for Laboratory classes & & & & & & \\
\hline $\begin{array}{l}\text { Completing the resources made me feel more } \\
\text { confident DURING the laboratory class }\end{array}$ & $1 \%$ & $2 \%$ & $11 \%$ & $54 \%$ & $32 \%$ & 142 \\
\hline $\begin{array}{l}\text { The resources were useful as revision tools AFTER } \\
\text { the laboratory activity was completed }\end{array}$ & $1 \%$ & $0 \%$ & $3 \%$ & $46 \%$ & $49 \%$ & 144 \\
\hline
\end{tabular}

In the current study, students repeatedly commented on the flexibility of the online adaptive lessons, and how it allowed them to study without having to go to the laboratory. More than half of the participants in this study accessed the resources from home and comments about practising in a low risk environment with the online adaptive resources also amplified the learning experience. This helped them to prepare for practical classes and provided a good revision resource for them. While this was important for all students enrolled in the subject, 
it was of particular value for online students to prepare them for a week long residential school as previous to this, the only resource they had was access to online lecture recordings. Williams, Birch and Hancock (2012) have demonstrated that there is evidence to suggest that repetitive use of resources leads to better subject outcomes for the student. Indeed, our quantitative findings indicated that students utilised the lessons extensively, with $30 \%$ of students reporting that they accessed each lesson five or more times and $84 \%$ of students accessed each lesson at least twice. It is therefore pleasing but unsurprising that students felt more confident when attending laboratory classes. Data was also collected on "time spent on the lesson". However, this data was unreliable as many students did not click on the lesson completed button. Any future lessons will be designed to address this so that the lesson engagement time can be analysed.

An additional feature that students valued was the provision of instant feedback, which assisted in their learning and cemented knowledge. Due to limitations to extending laboratory hours for self-guided study outside of class time, the adaptive lessons helped students identify strengths and weaknesses in their knowledge, which they could then concentrate on when laboratory staff were available during class time.

Based on the success of this approach in teaching diverse anatomy cohorts, we are currently evaluating the use of adaptive technologies in other large, service taught subjects such as physiology taught to very large allied health cohorts that include nursing with similar success.

\section{References}

Adams Becker S, Brown M, Dahlstrom E, Davis A, DePaul K, Diaz V, Pomerantz J. (2018). NMC Horizon Report: 2018 Higher Education Edition. 1st Ed. Louisville, CO: EDUCAUSE. 60 p.

URL: https://library.educause.edu/ /media/files/library/2018/8/2018horizonreport.pdf

Chen C. (2010). Information visualization. Computational Statistics, 2, 387-403.

De Boer, D. \& Collis, B. (2005) 'Becoming more systematic about flexible learning: Beyond time and distance', ALT-J', Research in Learning Technology, 13(1), 33-48

Estai M, Bunt S. (2016). Best teaching practices in anatomy education: A critical review. Annals of Anatomy 208, 151-157.

Green RA, Whitburn LY, Zacharias A, Byrne G, Hughes DL. (2018). The relationship between student engagement with online content and achievement in a blended learning anatomy course. Anatomical Sciences Education, 11(5), 471-477.

Kruzicevic, S.M., Barisic, K.J., Esteban, C.D., Sapunar, D, Puljak, L. (2012). Predictors of attrition and academic success of medical students: A 30-year retrospective study. PLOS ONE, 7(6), e39144. https://doi.org/10.1371/journal.pone.0039144

Makransky, G., Thisgaard, M,W., \& Gadegaard, H. (2016). Virtual simulations as preparation for lab exercises: Assessing learning of key laboratory skills in 
microbiology and improvement of essential non-cognitive skills. PLOS ONE, 11(6), 111. Doi:10.1371/journal.pone.0155895

Polly, P., Marcus, N., Maguire, D., Belinson, Z., \& Velan, G. (2014). Evaluation of an adaptive virtual laboratory environment using Western Blotting for diagnosis of disease. BMC Medical Education, 14(1), 222. Doi :10.1186/1472-6920-14-222.

Smart Sparrow. (2018). Adaptive learning technology. Smart Sparrow Pty Ltd., Sydney, NSW, Australia. URL: https://www.smartsparrow.com/ [accessed 21 January 2019].

Williams A, Birch E, Hancock P. (2012). The impact of online lecture recordings on student performance. Australasian Journal of Educational Technology, 28(2), 199-213.

Wong V, Smith AJ, Hawkins NJ, Kumar RK, Young N, Kyaw M, Velan GM. (2015). Adaptive tutorials versus web-based resources in radiology: A mixed methods comparison of efficacy and student engagement. Academic Radiology, 22, 1299-1307. 